\title{
Endoscopic sinus surgery in patients with cystic fibrosis: A systematic review and meta-analysis of pulmonary function
}

\author{
K.I. Macdonald'1', A. Gipsman², A. Magit², M. Fandino'1, E. Massoud³, \\ I.J. Witterick', P. Hong ${ }^{4}$ \\ Rhinology 50: 360-369, 2012 \\ DOI:10.4193/Rhino.11.271 \\ Department of Otolaryngology-Head and Neck Surgery, University of Toronto, Toronto, Ontario, Canada \\ Department of Otolaryngology-Head and Neck Surgery, University of California-San Diego, San Diego, CA, USA \\ *Received for publication: \\ December 30, 2011 \\ Division of Otolaryngology-Head and Neck Surgery, Department of Surgery, Dalhousie University, Halifax, Nova Scotia, Canada Accepted: July 16, 2012 \\ IWK Health Centre, Division of Otolaryngology-Head and Neck Surgery, Department of Surgery, Dalhousie University, Halifax, \\ Nova Scotia, Canada
}

\section{SUMMARY}

Introduction: The role of endoscopic sinus surgery (ESS) in patients with cystic fibrosis (CF) is not clearly defined.

Objective: To perform a systematic review of subjective and objective outcomes of ESS in CF.

Methods: A systematic review was performed using the keywords 'sinusitis,"sinus surgery,'nasal polyps' and 'cystic fibrosis.'The quality of papers was assessed using the NICE scoring scale. Outcomes included safety, subjective symptoms, objective endoscopy scores, days spent in hospital, courses of antibiotics, and pulmonary function tests (PFTs).

Results: Nineteen studies involving 586 patients were included in the review. There were four prospective cohort trials, and three were rated as good quality. There were no major complications attributable to ESS. There was consistent evidence in four cohort studies of improved sinonasal symptoms, including nasal obstruction, facial pain, headaches, rhinorrhea and olfaction. Three studies reported conflicting results in post-operative endoscopy scores. Three studies showed a decrease in days spent in hospital, and two showed a significant decrease in courses of intravenous antibiotics. A recent study, however, did not show a difference in either days spent in hospital or courses of antibiotics. Pulmonary function tests were not improved by ESS in six cohort trials, and one small study found significant improvement. A meta-analysis of FEV1 scores confirmed no significant difference.

Conclusion: The most consistent findings of this review were that ESS in patients with CF is safe, produces symptomatic benefit, and does not consistently improve PFTs. There were more conflicting results with regards to endoscopy scores, days spent in hospital, and courses of intravenous antibiotics. Future prospective studies, utilizing validated quality of life, symptom and endoscopy scales, are needed to further elucidate the role of ESS in the management of chronic rhinosinusitis in CF patients.

Key words: cystic fibrosis, sinus surgery, outcomes, chronic sinusitis

\section{Introduction}

Cystic fibrosis (CF) is the most common lethal autosomal recessive disorder in the Caucasian population ${ }^{(1)}$. It is a multisystem disorder mostly of exocrine glands that affects the lungs, intestines, pancreas and liver. Pulmonary and sinonasal involvement occur in $90-100 \%$ of patients, and up to $86 \%$ of children have nasal polyps at some time in their disease course ${ }^{(2,3)}$. The universal airway model has been demonstrated in asthma and chronic obstructive pulmonary disease, and may eventually prove particularly applicable to CF, especially as lung disease is the primary cause of mortality in this population ${ }^{(4-9)}$. Medical advancements have more than doubled the life 
expectancy of CF patients in recent years ${ }^{(10)}$. This has lead to an increased focus on morbidity, including sinonasal disease. Chronic rhinosinusitis (CRS) has been shown to have a negative effect on quality of life in both the general population (11-14), and in patients with $\mathrm{CF}^{(15,16)}$. Although medical treatments such as topical corticosteroids and mucolytics have shown benefit ${ }^{(17,18)}$, the treatment of CRS in CF patients has not been adequately studied. This includes endoscopic sinus surgery (ESS), where the role in CF patients is debatable ${ }^{(9)}$.

The authors performed a systematic review of current medical literature of ESS in CF patients in effort to clarify: 1) the quality of available evidence for ESS in CF patients, 2) the efficacy of ESS in CF patients, as measured by subjective and objective outcomes, and 3) the safety of ESS in CF patients.

\section{Methods}

A systematic review was performed using Medline, EMBASE and Central databases. The terms used included 'sinusitis,"sinus surgery,',nasal polyps' and 'cystic fibrosis' (limited to human, clinical trials, items with abstracts). The search was updated periodically until May 2012.

Abstracts were then reviewed independently by two of the authors (AEM and AG). References were cross-referenced to ensure all relevant papers were included. After collaboration, relevant abstracts were chosen for full-article review. Inclusion criteria were: papers published from 1980 onwards, published series of 10 or more patients, and a clear description of outcome measures used.

The year of 1980 was chosen because ESS was not popularized until well after this time. In addition, many studies before 1980 had very few patients and poorly reported outcomes. Non-

English papers were excluded. All data from the selected papers were extracted independently and were quality assessed by two authors.

Given the high variability of subjective and objective outcome measures associated with CRS studies, specific outcomes were not required for inclusion in our review. In addition, there were no adjustments made for differences in postoperative management of CRS. The goal was instead to attempt to group and analyze studies that employed any subjective and/or objective measures.

Papers were graded using the NICE (National Institute for Health and Clinical Excellence) scoring scale for case series (Appendix). The NICE scale has been previously used in systematic reviews in Otolaryngology ${ }^{(19)}$. It is based on eight items, each given a score of zero or one. Scores equal to or less than three indicate poor quality, four and five fair, and six or greater good quality. Studies were also graded on level of evidence according to the Oxford Centre for Evidence-Based Medicine 2011 Levels of Evidence ${ }^{(20)}$. For pooled analysis we used Review Manager (RevMan, version
5.1. Copenhagen: The Nordic Cochrane Centre, The Cochrane Collaboration, 2011). Given the likelihood of inter-study variability, we anticipated heterogeneity in outcome measurement and reporting across the studies. A random effect model was used to combine results across studies if possible. Heterogeneity was assessed by the $\mathrm{I}^{2}$ statistic.

Quantitative analysis was performed for those studies reporting similar objective outcome measurements and comparisons pre and post-operatively. For pulmonary function tests, the mean and standard deviations at 6 months postoperatively, compared to preoperative values, were chosen as the summary measures. If authors separately reported FEV ${ }_{1}$ and FVC the ratio of both parameters was calculated to allow pooling of results for a metaanalysis. The mean difference and $95 \%$ confidence intervals (Cls) were calculated to determine the overall effect size. A p-value < 0.05 was considered significant.

\section{Results}

The study selection process is shown in Figure 1. One hundred and seventy-three abstracts that described outcomes associated with ESS in CF patients were initially reviewed. Using the above inclusion and exclusion criteria, 45 of these were chosen for full length-article review. Upon further analysis, 26 articles were excluded, leaving 19 studies for the final review ${ }^{(7,21-38)}$. The majority of studies were excluded because: 1) ESS was not the primary intervention; 2) ESS was combined with other more prominent intervention(s); 3) outcome measures were not reported or were poorly defined; and 4) sample size of less than ten patients.

The 19 studies included in the review enrolled a total of 586 patients. Eight of the studies were published in the 1990's, six in the 2000's and five after 2010 (Table 1). The numbers of subjects ranged from 10 to 82 , with mostly paediatric and young adult patients. The majority of studies reported at least six months follow-up postoperatively.

There were 15 retrospective reviews, three prospective cohort studies, and one prospective case-control series (24) (Table 2). Using the NICE score as a guide, most were poor or fair quality, with three studies qualifying as good quality (NICE score 6) ${ }^{(21,27)}$. There were several subjective and objective outcomes measured (Table 2). For the purpose of this review, these were grouped into safety, subjective outcomes (symptoms), objective measures (endoscopy scores and rates of revision surgery), and extra-sinonasal outcomes, (length of hospital stay, courses of IV antibiotics, pulmonary function tests (PFTs), and post-lung transplant bacteriology). Table 3 shows major groupings with at least two studies, as well as level of evidence and summary of overall findings.

The details of endoscopic sinus surgery were described in fifteen studies ${ }^{(7,21-23,25-27,31-38)}$. The vast majority of procedures described included polypectomy, antrostomy, and ethmoidec- 
Table 1. Study characteristics and NICE quality score.

\begin{tabular}{|c|c|c|c|c|c|}
\hline Author & Year of publication & Subjects & $\begin{array}{l}\text { Mean Age } \pm \text { SD } \\
\text { (range) }\end{array}$ & $\begin{array}{l}\text { Follow-up mean } \pm \text { SD in } \\
\text { months (range or minimum) }\end{array}$ & NICE score (/8) \\
\hline Kempainen ${ }^{(37)}$ & 2012 & 32 & $26.3 \pm 6.9$ & 12 & 5 \\
\hline Vital (38) & 2012 & 82 & $26.8(25.1-28.5)$ & 12 & 2 \\
\hline Virgin ${ }^{(36)}$ & 2012 & 22 & $26.5(19-43)$ & 16 & 6 \\
\hline Osborn ${ }^{(7)}$ & 2011 & 41 & $11.9(5-18)$ & (12) & 4 \\
\hline Rickert ${ }^{(28)}$ & 2010 & 49 & $10.8(2-39)$ & $87.6(15.6-180)$ & 4 \\
\hline Khalid (24) & 2009 & 20 & $30.2 \pm 12.3(18-58)$ & $13.1 \pm 7.9$ & 5 \\
\hline Keck $^{(21)}$ & 2007 & 26 & $(3-33)$ & $23(6-74)$ & 6 \\
\hline Shatz ${ }^{(32)}$ & 2006 & 15 & $13.8(9-19)$ & $42(8-84)$ & 2 \\
\hline Jarrett $^{(23)}$ & 2004 & 17 & $(4-16)$ & (12) & 4 \\
\hline Yung ${ }^{(33)}$ & 2002 & 12 & $9(5-16)$ & (6) & 3 \\
\hline Rosbe ${ }^{(29)}$ & 2001 & 66 & $17 \pm 9.1$ & (6) & 4 \\
\hline Schulte ${ }^{(31)}$ & 1998 & 23 & $(3-69)$ & (6) & 1 \\
\hline Madonna ${ }^{(25)}$ & 1997 & 15 & $(5-24)$ & NR & 4 \\
\hline Triglia ${ }^{(34)}$ & 1997 & 27 & $12.6(4-18)$ & $39(6-132)$ & 4 \\
\hline Rowe-Jones ${ }^{(30)}$ & 1996 & 46 & $\mathrm{NR}^{*}$ & $28(1-72)$ & 2 \\
\hline Gentile ${ }^{(35)}$ & 1996 & 11 & $14.9(6-25)$ & $21(3-48)$ & 2 \\
\hline Nishioka ${ }^{(27)}$ & 1995 & 21 & $12.3(4-25)$ & $34.3(18-46)$ & 6 \\
\hline Moss $^{(26)}$ & 1995 & 51 & $\mathrm{NR}^{*}$ & (12) & 4 \\
\hline Cuyler (22) & 1992 & 10 & $N R^{*}$ & $24(30-42)$ & 2 \\
\hline
\end{tabular}

*NR: Not reported

$7,23,25,29,36,37$

tomy. Sphenoidotomy and frontal recess exploration were less uniformly performed. Three studies examined the benefit of a surgical intervention or procedure in addition to ESS. Shatz et al., (32) compared 15 paediatric patients who had a combined ESS and Caldwell-Luc procedure to a matched group who had ESS alone. The ESS + Caldwell-Luc group showed a significant decrease in number of hospital admissions, courses of IV antibiotics, and increase in forced expiratory volume in 1 second (FEV1) in the six months after surgery compared to the six months before surgery (all $p<0.006$ ). Moss et al., ${ }^{(26)}$ performed serial antimicrobial lavage in 51 patients for at least 7 days after surgery. They reported a significant reduction in the revision surgery rates at 2 years follow-up $(p=0.03)$. Virgin et al., ${ }^{\left({ }^{(6)}\right)}$ recently performed a modified endoscopic medial maxillectomy (MEMM) in 22 patients, and found a significant improvement in sinonasal symptoms, endoscopy scores, and hospital admissions due to respiratory complications, but not in FEV1 scores.

\section{Safety}

Eight of 19 studies commented on complications. Seven studies 


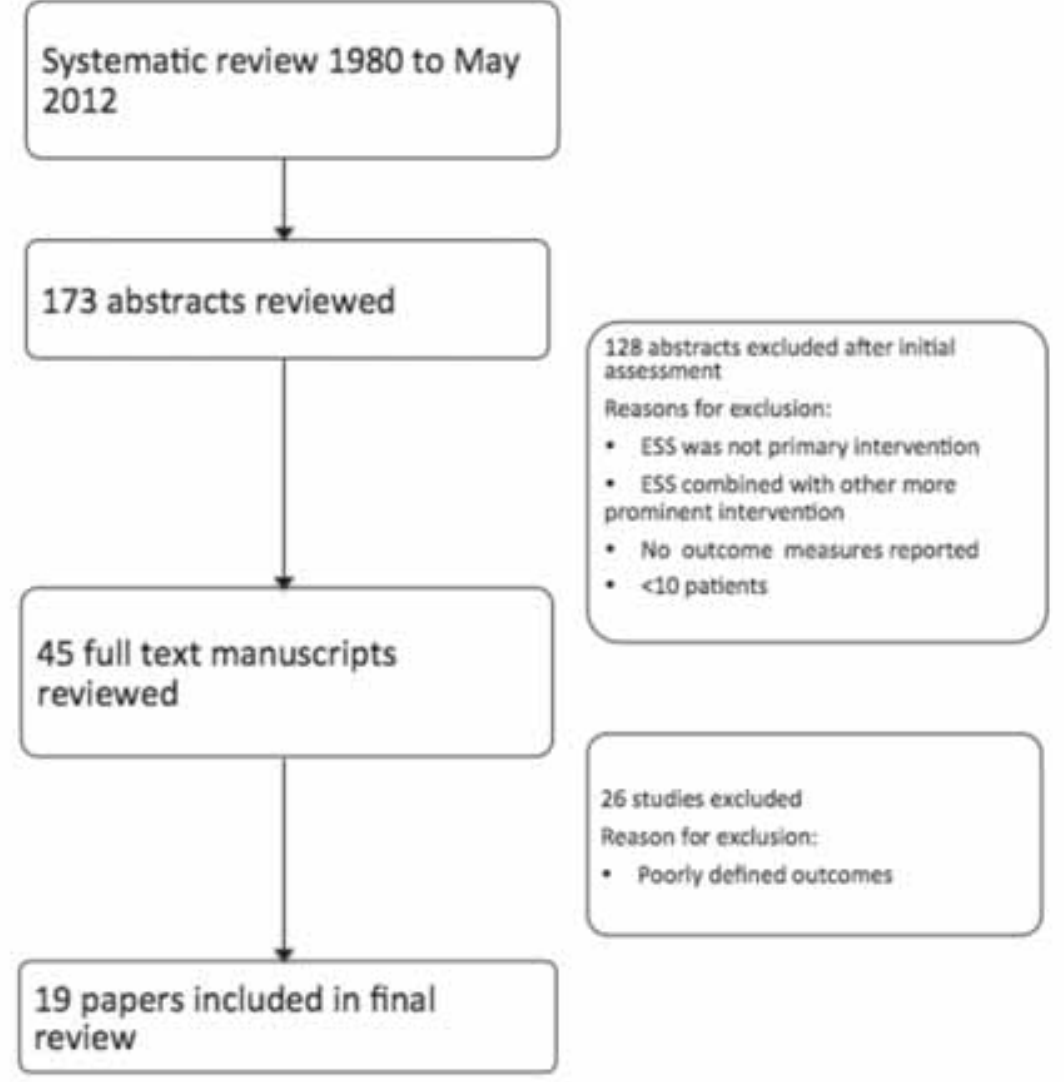

Figure 1. Literature search algorithm.

of 178 patients specifically stated there were no, or few and minor, complications due to sinus surgery in the study period $(22,28,31,32,34,36,37)$. Minor complications were described in one study as mild bleeding intraoperatively ${ }^{\left({ }^{37)}\right.}$. Keck et al., (26 patients) described two patients that developed intracranial complications, one with meningitis and another with a frontal abscess, in the post-operative period ${ }^{(21)}$. These were discussed in detail. Both patients previously had mucopyoceles with extensive sinus surgery, and it was felt that the ESS performed in the study period did not contribute to these complications. Virgin et al., reported on three patients who died from pulmonary complications, postoperatively ${ }^{(36)}$. The authors did not believe these were related to surgery.

Although not explicitly stated in all studies, there were no reported major complications attributed to ESS in any of the 19 studies comprising 586 patients.

\section{Subjective Outcomes}

Major sinonasal symptoms were the most commonly studied outcomes, reported in ten of the studies (21,24,27,30-36). These included nasal obstruction, rhinorrhea, headaches, facial pain, and olfaction. However, detailed reporting with symptom scales and statistical analysis was performed in four studies, $(21,24,27,36)$ whereas many studies simply stated whether patients reported improvement or not. For example, Triglia et al., reported that of 27 paediatric patients with a mean follow-up of one year, nasal obstruction and rhinorrhea decreased in $84 \%$ and $68 \%$ of cases, respectively ${ }^{\left({ }^{34)}\right.}$. These four studies were the only ones that scored five or six on the NICE scale (all other studies scored lower).

A pooled analysis was not possible because no two studies used the same questionnaire. Virgin et al., used the 22-item Sinonasal Outcome Test (SNOT-22) questionnaire prospectively in 21 patients up to one year postoperatively ${ }^{(36)}$. Khalid et al., examined 20 adult patients at six months follow-up with the Rhinosinusitis Disability Index (RSDI) and the Chronic Sinusitis Survey (CSS) ${ }^{(24)}$. Keck et al., used a non-validated Likert scale to examine symptom outcomes in 26 patients, with at least six months of follow-up ${ }^{(21)}$, and Nishioka generated a scale in 21 patients with at least 18 months of follow-up (27).

All four studies found a significant decrease in all sinonasal symptoms, although Keck et al., did not find a difference in olfaction, and Nishioka et al., did not find a difference in headaches. Virgin et al., found sustained significant improvements in SNOT-22 scores at one year, postoperatively.

The study by Khalid et al., was a prospective case-control trial, 


\begin{tabular}{|c|c|c|}
\hline Author & Outcomes Measured & Resultsa \\
\hline Kempainen (37) & $\begin{array}{l}\text { PFTs } \\
\text { Hospital admissions (pulmonary exacerbations) } \\
\text { IV antibiotics }\end{array}$ & No significant change \\
\hline Vital (38) & $\begin{array}{l}\text { Sinus and lung microbiology, ESS performed post lung } \\
\text { transplant }\end{array}$ & $\begin{array}{l}\text { Direct correlation between sinus colonization \& lung allograft } \\
\text { infection }(p<0.0001) \text { post lung transplant }\end{array}$ \\
\hline Virgin ${ }^{(36)}$ & $\begin{array}{l}\text { Symptoms: obstruction, facial pain, rhinorrhea, olfaction, } \\
\text { cough (SNOT-22) } \\
\text { Endoscopy score (Lund-Kennedy) } \\
\text { PFTs }{ }^{b} \\
\text { Hospital admissions (pulmonary exacerbations) }\end{array}$ & $\begin{array}{l}\text { Significant improvement in symptoms, }(p<0.0001) \text { endoscopy } \\
\text { score }(p<0.0001) \text { and hospital admissions }(p<0.05) \\
\text { No significant change in PFTs }\end{array}$ \\
\hline Osborn ${ }^{(7)}$ & $\begin{array}{l}\text { PFTs }{ }^{b} \\
\text { Respiratory tract microbial pathogens }\end{array}$ & No significant change \\
\hline Rickert ${ }^{(28)}$ & $\begin{array}{l}\text { Endoscopic polyp score (Malm score) } \\
\text { Need for revision surgery }\end{array}$ & $\begin{array}{l}\text { Preoperative Malm score predicted need for revision surgery (all } \\
p \leq 0.04 \text { ) }\end{array}$ \\
\hline Khalid ${ }^{(24)}$ & $\begin{array}{l}\text { Symptoms: obstruction, rhinorrhea, headaches, facial } \\
\text { pain, quality of life (RSDI \& CSS }) \\
\text { Endoscopy score (Lund-Kennedy) }\end{array}$ & $\begin{array}{l}\text { Significant improvement in all symptoms (all } p \leq 0.004 \text { ) except } \\
\text { medication usage (CSS) } \\
\text { No change in endoscopy score }\end{array}$ \\
\hline Keck $^{(21)}$ & $\begin{array}{l}\text { Symptoms: obstruction, rhinorrhea, headaches, facial } \\
\text { pain, olfaction (Likert scale) } \\
\text { Polyps (Malm score) }\end{array}$ & $\begin{array}{l}\text { Significant decrease in all (all } p<0.003 \text { ) except olfaction } \\
\text { Significant decrease }(p<0.01)\end{array}$ \\
\hline Shatz ${ }^{(32)}$ & $\begin{array}{l}\text { Symptoms: obstruction, rhinorrhea, headaches, facial } \\
\text { pain } \\
\text { Endoscopy: polyps, conchal hypertrophy } \\
\text { Hospital days and IV antibiotics } \\
\text { PFTs }^{b}\end{array}$ & $\begin{array}{l}\text { Significant decrease \# of hospital admissions, PFTs, and courses } \\
\text { IV antibiotics (all } p<0.006 \text { ) } \\
\text { Statistical analysis not applied to other outcomes }\end{array}$ \\
\hline Jarrett ${ }^{(23)}$ & $\mathrm{PFTs}^{\mathrm{b}}$ & No significant change \\
\hline Yung (33) & $\begin{array}{l}\text { Symptoms: obstruction, rhinorrhea, olfaction, headache, } \\
\text { facial pain } \\
\text { Nasal endoscopy }\end{array}$ & No statistical analysis \\
\hline Rosbe ${ }^{(29)}$ & $\begin{array}{l}\text { Hospital days } \\
\text { Oral \& inhaled steroid use } \\
\text { PFTs }^{\mathrm{b}}\end{array}$ & $\begin{array}{l}\text { Significant reduction }(p<0.001) \\
\text { No significant change } \\
\text { No significant change }\end{array}$ \\
\hline Schulte ${ }^{(31)}$ & $\begin{array}{l}\text { Overall symptom recurrence } \\
\text { Rates of revision surgery }\end{array}$ & No statistical analysis \\
\hline Madonna ${ }^{(25)}$ & $\mathrm{PFTs}^{\mathrm{b}}$ & No significant change \\
\hline Triglia ${ }^{(34)}$ & $\begin{array}{l}\text { Symptoms: obstruction, rhinorrhea } \\
\text { Endoscopy (polyps) } \\
\text { PFTs }{ }^{\text {b }} \\
\text { Courses IV antibiotics }\end{array}$ & $\begin{array}{l}\text { Significant decrease in the number of courses of antibiotics (all } \\
p<0.0001 \text { ) } \\
\text { Statistical analysis not applied to other outcomes }\end{array}$ \\
\hline Rowe-Jones ${ }^{(30)}$ & Symptoms: obstruction, rhinorrhea, headache & 40/46 improved, no statistical analysis \\
\hline Gentile ${ }^{(35)}$ & Symptoms: obstruction and headache & No statistical analysis \\
\hline Nishioka ${ }^{(27)}$ & $\begin{array}{l}\text { Symptoms: obstruction, olfaction, rhinorrhea, head- } \\
\text { aches, facial pain, activity level, self-reported sinus } \\
\text { infections }\end{array}$ & Significant improvement in all (all $p<0.004$ ) except headaches \\
\hline Moss ${ }^{(26)}$ & $\begin{array}{l}\text { Need for revision surgery, compared ESS and serial anti- } \\
\text { microbial lavage (ESSAL) to conventional ESS }\end{array}$ & $\begin{array}{l}\text { Significant reduction in revision surgery in ESSAL group at } 2 \\
\text { years follow-up }(p=0.03)\end{array}$ \\
\hline Cuyler (22) & Pre- and post-operative CT findings & No significant change \\
\hline
\end{tabular}

${ }^{a} \mathrm{p}$ scores are reported as the least significant score for a group of results.

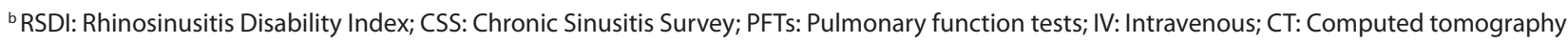




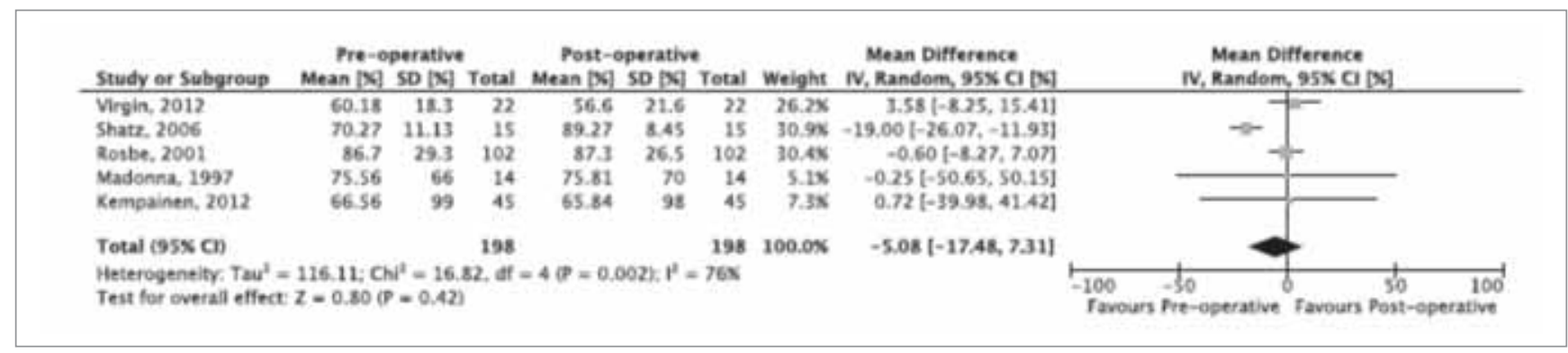

Figure 2. Literature search algorithm.

Table 3. Summary of studies using statistical analysis.

\begin{tabular}{|c|c|c|c|}
\hline Outcome & Study Characteristics & Level of Evidence $^{a}$ & Findings \\
\hline $\begin{array}{l}\text { Symptoms (obstruction, } \\
\text { facial pain, headaches, } \\
\text { rhinorrhea, olfaction) }\end{array}$ & $\begin{array}{l}\text { Two prospective cohorts }{ }^{(27,36)} \\
\text { One prospective case-control series }{ }^{(24)} \\
\text { One retrospective cohort }{ }^{(21)}\end{array}$ & 3 & Significant improvement in all studies \\
\hline Endoscopy Scores & $\begin{array}{l}\text { Two prospective cohorts }(24,36) \\
\text { One retrospective cohort }{ }^{(21)}\end{array}$ & 3 & $\begin{array}{l}\text { Two studies showed significant improvement } \\
\text { (Virgin et al., Keck et al.). One showed no differ- } \\
\text { ence (Khalid et al.) }\end{array}$ \\
\hline Hospital admissions & $\begin{array}{l}\text { One prospective cohort }{ }^{(36)} \\
\text { Three retrospective cohorts }(29,32,37)\end{array}$ & 3 & $\begin{array}{l}\text { Three studies showed significant improvement } \\
\text { (Virgen et al. Rosbe et al. Shatz et al.). One showed } \\
\text { no difference (Kempainen et al.) }\end{array}$ \\
\hline $\begin{array}{l}\text { Courses of intravenous } \\
\text { antibiotics }\end{array}$ & Three retrospective cohorts ${ }^{(32,34,37)}$ & 3 & $\begin{array}{l}\text { Two studies showed significant reduction (Triglia } \\
\text { et al., Shatz et al.). One showed no difference } \\
\text { (Kempainen et al.) }\end{array}$ \\
\hline Pulmonary function tests & $\begin{array}{l}\text { One prospective cohort }{ }^{(36)} \\
\text { Six retrospective cohorts }(7,23,25,29,32,37)\end{array}$ & 3 & $\begin{array}{l}\text { Forrest plot meta-analysis showed no significant } \\
\text { difference }(p=0.42)\end{array}$ \\
\hline
\end{tabular}

a Oxford Centre for Evidence-Based Medicine

comparing ESS in patients with CF to matched controls without $\mathrm{CF}{ }^{(24)}$. Although, they found worse baseline $\mathrm{CT}$ and endoscopy scores in their CF population ( $p<0.05$ ), the degree of improvement on endoscopy scores and subjective questionnaires was similar in both groups $(p>0.07)$.

\section{Objective Outcomes}

Endoscopy Scores. Objective outcomes were reported in twelve studies, with statistically analyzed data in seven of the studies. Four studies examined endoscopy scores ${ }^{(21,24,28,36)}$. Khalid et al., found no difference in Lund-Kennedy scores postoperatively in either group of 20 patients with CF and 20 matched controls, at six months follow-up ${ }^{(24)}$. This is in contrast to the results by Virgin et al., which showed a sustained significant improvement in Lund-Kennedy scores up to one year, postoperatively ${ }^{(36)}$. Keck et al., found a significant decrease in polyps in 26 patients with at least eight months follow-up using the Malm score ${ }^{(21)}$. Rickert et al., also used the Malm score to grade polyps preoperatively, and found that patients with higher polyp severity were more likely to need revision surgery $(p \leq 0.04)^{(28)}$.
Predictors of Revision Surgery. Factors predictive of revision surgery were examined in two studies. In addition the study described above by Rickert et al., Moss and colleagues found the need for revision surgery was significantly reduced in patients who received serial antimicrobial lavage compared to patients who received conventional ESS (26).

\section{Extra-Sinonasal Outcomes}

Hospital admissions. Four studies compared pre- and postoperative days spent in hospital. These admissions were usually noted to be secondary to pulmonary exacerbations. Two studies found a significant decrease in the 6 months after surgery compared to the 6 months before surgery $(p<0.006)^{(29,32)}$, and another reported similar findings on 12 month follow-up ${ }^{(36)}$. However, a recently published larger retrospective review of 32 patients by Kempainen and colleagues found no difference in number of days spent in hospital when comparing 6 months pre- and post-operatively, as well as between 12 months, pre- and post-operatively ${ }^{(37)}$. 
Courses of Antibiotics. Three studies compared the number of courses of intravenous antibiotics prescribed for lung infections, pre- and postoperatively. Two found a significant reduction after ESS ${ }^{(32,34)}$, whereas the review by Kempainen and colleagues did not show a difference ${ }^{(37)}$.

Pulmonary Function Tests. Pulmonary function tests (PFTs) were compared pre- and postoperatively in eight studies; seven of these used statistical analyses $(7,23,25,29,32,36,37)$. Six studies, all of which had relatively high NICE scores of 4 and above, found no post-operative change in PFTs in CF patients undergoing ESS $(7,23,25,29,36,37)$. These included 193 patients with at least six months follow-up, postoperatively. Although Jarrett et al., found significant improvement in PFTs at one-month postoperatively, these changes were not sustained at six and 12 months, postoperatively ${ }^{(23)}$.

Shatz et al., (NICE score 2) retrospectively examined 15 patients and found significant improvements in FEV1 scores at 6 months, postoperatively ${ }^{(32)}$. These values tended to decrease at one year postoperatively, but there were insufficient patient numbers for statistical analysis.

An eighth study enrolled 15 patients and examined PFTs preoperatively. The authors similarly did not find significant improvement in PFTs postoperatively, but did not report follow-up ${ }^{(25)}$.

Quantitative analysis was performed grouping 4 retrospective and 1 prospective cohort trials that reported the same PFTs parameters. Effect estimates for each study as well as combined results are shown via Forest plots (Figure 2).

The pooled mean difference $\left(95 \% \mathrm{Cl}\right.$ ) of $\mathrm{FEV}_{1} \%$ (also reported as ratio of $\left.\mathrm{FEV}_{1} / \mathrm{FVC}\right)$ after ESS in $198 \mathrm{CF}$ patients was $-5.08(95 \% \mathrm{Cl}$, $-17.48,7.31)$. High heterogeneity was seen across studies ( $I^{2}$ : $76 \%$ ), leading to a non-statistically significant difference in FEV $\%$ after ESS ( $p=0.42$ ). This wide confidence interval is not surprising as there was great variability in the results pooled from the five studies, mainly due to the limited sample sizes.

Post-lung Transplant Microbiology. Vital et al., described ESS and diligent post-operative care in 82 patients who had recently recovered from lung transplantation. Their results showed a highly significant correlation of sinus colonization and lung allograft infection post-ESS $(p<0.0001)^{(38)}$. ESS resulted in a reduced sinonasal bacterial load, which correlated with reduced bacterial cultures on bronchoalveolar lavage. The authors theorized that routine ESS after lung transplant in CF patients may help prevent pulmonary complications including allograft rejection.

\section{Other outcomes}

One study found that ESS did not affect respiratory tract microbial pathogens ${ }^{(7)}$, and another found no difference in oral and inhaled steroid usage ${ }^{(29)}$

\section{Discussion}

When CF was first recognized as a specific disease entity in 1938, most patients died shortly after diagnosis ${ }^{(39)}$. In 1960, patients with CF were not expected to live past childhood ${ }^{(40)}$. In the last 50 years, the understanding of the natural course of CF has led to better treatment of respiratory infections, enhancement of mucociliary clearance and improved nutritional status ${ }^{(39)}$. As a result, survival in CF patients has progressively improved over the last 4 decades, and today carries a median survival into the sixth decade. This improvement in survival has translated into a focus on decreasing morbidity.

CRS in CF patients deserves special attention for several reasons. Symptoms and findings of CRS are almost ubiquitous in CF patients ${ }^{(22,35)}$. Over $80 \%$ have nasal obstruction, one quarter have anosmia, and over half experience rhinorrhea and daily headaches. Almost all patients have abnormal endoscopic exams ${ }^{(41-43)}$. Specific imaging characteristics have been described in CF patients, including frontal and sphenoid sinus hypoplasia, demineralized uncinate processes, and medial displacement of the lateral nasal wall ${ }^{(44)}$. Finally, CF should theoretically provide a model example for the unified airway theory. Almost all patients have both CRS and decreased lung function, and the underlying pathophysiological mechanism in CF helps explain the disease manifestations in both systems. However, our findings suggest the unified airway model may not be applicable to CRS in CF patients, as discussed further below.

This is the first systematic review of ESS in CF patients, summarizing findings of 19 studies employing a total of 586 patients.

As there was a lack of consistent outcomes a meta-analysis was just performed only for PFTs. Most trials were retrospective, and three were graded as good quality according to the NICE scale. Some studies contained only qualitative data. Qualitative research is capable of being methodologically sound, and has a role for inclusion in systematic reviews ${ }^{(45,46)}$. A strict set of inclusion criteria, for example including only randomized controlled trials, would have yielded no studies. The authors felt that the inclusion of these 19 studies instead provides a more comprehensive picture of the body of literature of ESS in CF patients. We however acknowledge the risks of selection bias, outcome assessor bias due to lack of blinding as well as attrition bias. The small number of studies suitable for meta-analysis did not allow us to accurately perform a quantitative assessment of publication bias (e.g. funnel plot).

ESS in CF is a safe surgical procedure, which is concordant with the safety of ESS in the general population ${ }^{(47)}$. The safety of ESS in CF patients has previously been shown to be similar to nonCF patients ${ }^{(48)}$.

Several studies are worth discussing further, including the four 
that examined subjective symptoms and objective endoscopy scores, and the seven that compared PFTs.

Four studies examining subjective symptoms showed a significant decrease in many of the major symptoms of CRS, including nasal obstruction, rhinorrhea, headaches, facial pain, and olfaction ${ }^{(21,24,27,36)}$. These studies comprised 79 patients with at least 6 months of follow-up, postoperatively.

Three studies compared pre- and post-operative endoscopic disease burden, with conflicting results. Interestingly, the prospective case-control study by Khalid et al., did not find a difference in either the CF patients or the control group of non-CF patients ${ }^{(24)}$. With the same scale, Virgin et al., found a sustained improvement at one year postoperatively ${ }^{(36)}$. Keck et al., found a significant improvement in the Malm score ${ }^{(21)}$. Previous wellconducted studies have shown endoscopic post-operative improvement in CRS patients ${ }^{(49)}$. Future prospective trials using validated endoscopy scores (Lund-Kennedy, POSE, Malm) will help determine the objective benefit of ESS in CF.

Perhaps the most interesting finding of this review is the six studies involving 163 CF patients that did not show a sustained benefit in PFTs after ESS. When looking at the overall estimate with a meta-analysis, no significant difference was found. This is in contrast to CRS in patients with asthma, in which ESS has resulted in sustained improvement in PFTs (50,51).

The findings of this review do not clearly support the unified airway theory model. Perhaps the underlying pathophysiological mechanism of impaired mucociliary function in CF is such that pulmonary function is independent of sinonasal disease. While discussing their results, Osborn et al., suggested the lack of improvement in PFTs may be from the infectious nature of lung disease in $\mathrm{CF}^{(7)}$. Multicenter case control or cohort studies are required to increase sample size and allow a more precise estimate of the role of ESS on outcomes in CF.

The lack of randomized controlled trials (RCTs) examining ESS in CF patients is not surprising. There are few RCTs of medical treatments of CRS in CF patients ${ }^{(17,18,42)}$. In the general CRS population, a Cochrane review of ESS efficacy identified only three studies involving 212 patients that met inclusion criteria. This review excluded studies which enrolled CF patients ${ }^{(47)}$. It is debatable whether RCTs involving surgical procedures are possible or ethical ${ }^{(47)}$. Despite the variety of outcomes and number of lower quality trials, this paper meets the criteria for a systematic review ${ }^{(52)}$.

The quality of research of ESS in CF patients appears to be improving. The studies in the last 10 years are of higher quality; studies before 2000 had an average NICE score of 3.1, compared to 4.1 in studies after 2000 . There is a trend towards using validated subjective and objective scales in assessing outcomes. For these reasons along with the improved mortality and awareness of ESS in CF patients, we should see more consistent clinical trials, potentially amenable to a meta-analysis. Other outcomes and variables should be analyzed, including various CF genotypes and phenotypes, and their response to surgery ${ }^{(53)}$. There were several articles excluded which did examine the efficacy of ESS in CF, and were close to inclusion in this review, but were felt to be lacking either in quality of outcomes, or number of patients. The authors however tried to be generous in papers that were accepted in the review, mostly for the reasons stated above. For example, Becker and colleagues ${ }^{(54)}$ examined 81 patients with CF. Sixty-one had ESS, and 41 had pre- and post-operative PFTs. The Lund-Mackay score of the preoperative CT scan was significantly predictive of the need for repeat surgery. There was no significant difference in PFT values. This article was excluded because the demographics of the $61 \mathrm{pa}-$ tients who had ESS were not separately described, but grouped with the initial 81 patients. We could not accurately represent this article, although it had meaningful results. The reader is encouraged to review several additional articles regarding ESS in $\mathrm{CF}$ if there is a desire to complete a more exhaustive search ${ }^{(54-60)}$.

\section{Conclusion}

This systematic review examining endoscopic sinus surgery in patients with cystic fibrosis included 19 studies described and 586 patients. There were 15 retrospective reviews, three prospective cohort studies, and one prospective case-control series. ESS in this population was safe. ESS produces a significant subjective benefit in major CRS symptoms, as shown in four studies. Three studies report conflicting results with regards to endoscopic improvement, postoperatively. Three studies showed a significant decrease in days spent in hospital postoperatively, and two found a significant decrease in the number of courses of intravenous antibiotics. A more recent study did not show a difference in either days spent in hospital or courses of antibiotics. Pulmonary function tests were not improved by ESS in six cohort trials, and a meta-analysis confirmed no significant difference. There is a need for further prospective trials examining the role ESS in CF patients, preferably utilizing validated scales.

\section{Conflict of interest}

The authors have no financial disclosure or conflicts of interest relevant to this work. 


\section{REFERENCES}

1. Ramsey B, Richardson MA. Impact of sinusitis in cystic fibrosis. J Allergy Clin Immunol. 1992; 90: 547-552.

2. Ryan MW. Diseases associated with chronic rhinosinusitis: what is the significance? Curr Opin Otolaryngol Head Neck Surg. 2008; 16: 231-236.

3. Weber SA, Ferrari GF. Incidence and evolution of nasal polyps in children and adolescents with cystic fibrosis. Braz J Otorhinolaryngol. 2008; 74: 16-20.

4. Krouse JH, Brown RW, Fineman SM, et al. Asthma and the unified airway. Otolaryngol Head Neck Surg. 2007; 136: S75-106.

5. Stelmach R, do Patrocinio TNM, Ribeiro $M$, Cukier A. Effect of treating allergic rhinitis with corticosteroids in patients with mildto-moderate persistent asthma. Chest. 2005; 128: 3140-3147

6. Watson WT, Becker AB, Simons FE. Treatment of allergic rhinitis with intranasal corticosteroids in patients with mild asthma: effect on lower airway responsiveness. J Allergy Clin Immunol. 1993; 91: 97-101.

7. Osborn AJ, Leung R, Ratjen F, James AL. Effect of endoscopic sinus surgery on pulmonary function and microbial pathogens in a pediatric population with cystic fibrosis. Arch Otolaryngol Head Neck Surg. 2011; 137: 542-547.

8. Rachelefsky GS, Katz RM, Siegel SC. Chronic sinus disease with associated reactive airway disease in children. Pediatrics. 1984; 73 : 526-529.

9. Yanagi K, Ishii A, Udagawa T, Haruna S, Moriyama $\mathrm{H}$. Effects of ESS on sinobronchial syndrome. Nippon Jibiinkoka Gakkai Kaiho. 2003; 106: 1030-1037.

10. Wilschanski M, Kerem E. New drugs for cystic fibrosis. Expert Opin Investig Drugs. 2011.

11. Macdonald KI, McNally JD, Massoud E. Quality of life and impact of surgery on patients with chronic rhinosinusitis. J Otolaryngol Head Neck Surg. 2009; 38: 286293.

12. Macdonald KI, McNally JD, Massoud E. The health and resource utilization of Canadians with chronic rhinosinusitis. Laryngoscope. 2009; 119: 184-189.

13. Soler ZM, Sauer D, Mace J, Smith TL. Impact of mucosal eosinophilia and nasal polyposis on quality-of-life outcomes after sinus surgery. Otolaryngol Head Neck Surg. 2010; 142: 64-71.

14. Dykewicz MS, Hamilos DL. Rhinitis and sinusitis. J Allergy Clin Immunol. 2010; 125: S103-115.

15. Nishioka GJ, Cook PR. Paranasal sinus disease in patients with cystic fibrosis. Otolaryngol Clin North Am. 1996; 29: 193-205.

16. Mainz JG, Koitschev A. Management of chronic rhinosinusitis in CF. J Cyst Fibros. 2009; 8 Suppl 1: S10-14.

17. Raynor EM, Butler A, Guill M, Bent JP, 3rd. Nasally inhaled dornase alfa in the postoperative management of chronic sinusitis due to cystic fibrosis. Arch Otolaryngol Head Neck Surg. 2000; 126: 581-583.

18. Hadfield PJ, Rowe-Jones JM, Mackay IS. A prospective treatment trial of nasal polyps in adults with cystic fibrosis. Rhinology. 2000; 38: 63-65

19. Thomas L, Drinnan M, Natesh B, Mehanna $H$, Jones T, Paleri V. Open conservation partial laryngectomy for laryngeal cancer: A systematic review of English language literature. Cancer Treat Rev. 2011.

20. Howick J Cl, Glasziou P, et al. OCEBM Levels of Evidence Working Group. The Oxford 2011 Levels of Evidence. Available at: http://www. cebm.net.index.aspx?o=5653. Accessed Sept. 1, 2011.

21. Keck T, Rozsasi A. Medium-term symptom outcomes after paranasal sinus surgery in children and young adults with cystic fibrosis. Laryngoscope. 2007; 117: 475-479.

22. Cuyler JP. Follow-up of endoscopic sinus surgery on children with cystic fibrosis. Arch Otolaryngol Head Neck Surg. 1992; 118: 505506.

23. Jarrett WA, Militsakh O, Anstad M, Manaligod J. Endoscopic sinus surgery in cystic fibrosis: effects on pulmonary function and ideal body weight. Ear Nose Throat J. 2004; 83: 118-121.

24. Khalid AN, Mace J, Smith TL. Outcomes of sinus surgery in adults with cystic fibrosis. Otolaryngol Head Neck Surg. 2009; 141: 358363.

25. Madonna D, Isaacson G, Rosenfeld RM, Panitch $\mathrm{H}$. Effect of sinus surgery on pulmonary function in patients with cystic fibrosis. Laryngoscope. 1997; 107: 328-331.

26. Moss RB, King VV. Management of sinusitis in cystic fibrosis by endoscopic surgery and serial antimicrobial lavage. Reduction in recurrence requiring surgery. Arch Otolaryngol Head Neck Surg. 1995; 121: 566572.

27. Nishioka GJ, Barbero GJ, Konig P, Parsons DS, Cook PR, Davis WE. Symptom outcome after functional endoscopic sinus surgery in patients with cystic fibrosis: a prospective study. Otolaryngol Head Neck Surg. 1995; 113: 440-445

28. Rickert S, Banuchi VE, Germana JD, Stewart MG, April MM. Cystic fibrosis and endoscopic sinus surgery: Relationship between nasal polyposis and likelihood of revision endoscopic sinus surgery in patients with cystic fibrosis. Arch Otolaryngol Head Neck Surg. 2010; 136: 988-992.

29. Rosbe KW, Jones DT, Rahbar R, Lahiri T, Auerbach AD. Endoscopic sinus surgery in cystic fibrosis: do patients benefit from surgery? Int J Pediatr Otorhinolaryngol. 2001; 61:113-119.

30. Rowe-Jones JM, Mackay IS. Endoscopic sinus surgery in the treatment of cystic fibrosis with nasal polyposis. Laryngoscope. 1996; 106: 1540-1544

31. Schulte DL, Kasperbauer JL. Safety of paranasal sinus surgery in patients with cystic fibrosis. Laryngoscope 1998; 108: 1813-1815.

32. Shatz A. Management of recurrent sinus disease in children with cystic fibrosis: a combined approach. Otolaryngol Head Neck Surg. 2006; 135: 248-252.

33. Yung MW, Gould J, Upton GJ. Nasal polyposis in children with cystic fibrosis: a long-term follow-up study. Ann Otol Rhinol Laryngol. 2002; 111: 1081-1086.

34. Triglia JM, Nicollas R. Nasal and sinus polyposis in children. Laryngoscope. 1997; 107: 963-966.

35. Gentile VG, Isaacson G. Patterns of sinusitis in cystic fibrosis. Laryngoscope. 1996; 106: 1005-1009.

36. Virgin FW, Rowe SM, Wade MB, et al. Extensive surgical and comprehensive postoperative medical management for cystic fibrosis chronic rhinosinusitis. Am J Rhinol Allergy. 2012; 26: 70-75.

37. Kempainen RR, Sajan JA, Pylkas AM, et al. Effect of Endoscopic Sinus Surgery on Pulmonary Status of Adults with Cystic Fibrosis. Otolaryngol Head Neck Surg. 2012 Apr 18 [Epub ahead of print].

38. Vital D, Hofer M, Boehler A, et al. Posttransplant sinus surgery in lung transplant recipients with cystic fibrosis: a single institutional experience. Eur Arch Otorhinolaryngol. 2012.

39. Cohen-Cymberknoh M, Shoseyov D, Kerem E. Managing cystic fibrosis: strategies that increase life expectancy and improve quality of life. Am J Respir Crit Care Med. 2011; 183: 1463-1471.

40. Britton JR. Effects of social class, sex, and region of residence on age at death from cystic fibrosis. BMJ. 1989; 298: 483-487.

41. Coste A, Gilain L, Roger G, et al. Endoscopic and CT-scan evaluation of rhinosinusitis in cystic fibrosis. Rhinology. 1995; 33: 152-156.

42. Robertson JM, Friedman EM, Rubin BK. Nasal and sinus disease in cystic fibrosis. Paediatr Respir Rev. 2008; 9: 213-219.

43. Brihaye P, Jorissen M, Clement PA. Chronic rhinosinusitis in cystic fibrosis (mucoviscidosis). Acta Otorhinolaryngol Belg. 1997; 51: 323-337.

44. Eggesbo HB, Sovik S, Dolvik S, Kolmannskog F. CT characterization of inflammatory paranasal sinus disease in cystic fibrosis. Acta Radiologica. 2002; 43: 21-28.

45. Dixon-Woods M, Sutton A, Shaw $R$, et al Appraising qualitative research for inclusion in systematic reviews: a quantitative and qualitative comparison of three methods. J Health Serv Res Policy. 2007; 12: 42-47.

46. Dixon-Woods M, Fitzpatrick R, Roberts K. Including qualitative research in systematic reviews: opportunities and problems. J Eval Clin Pract. 2001; 7: 125-133.

47. Khalil HS, Nunez DA. Functional endoscopic sinus surgery for chronic rhinosinusitis. Cochrane Database Syst Rev. 2006; 3: CD004458.

48. Lamberty JM, Rubin BK. The management of anaesthesia for patients with cystic fibrosis. Anaesthesia. 1985; 40: 448-459.

49. Wright ED, Agrawal S. Impact of perioperative systemic steroids on surgical outcomes in patients with chronic rhinosinusitis with polyposis: evaluation with the novel Perioperative Sinus Endoscopy (POSE) scoring system. Laryngoscope. 2007; 117: 1-28.

50. Batra PS, Kern RC, Tripathi A, et al. Outcome analysis of endoscopic sinus surgery in 
patients with nasal polyps and asthma. Laryngoscope. 2003; 113: 1703-1706.

51. Ikeda K, Tanno N, Tamura G, et al. Endoscopic sinus surgery improves pulmonary function in patients with asthma associated with chronic sinusitis. Ann Otol Rhinol Laryngol. 1999; 108: 355-359

52. Neely JG, Magit AE, Rich JT, et al. A practical guide to understanding systematic reviews and meta-analyses. Otolaryngol Head Neck Surg. 2010; 142: 6-14

53. Feuillet-Fieux MN, Lenoir G, Sermet I, et al. Nasal polyposis and cystic fibrosis(CF) review of the literature. Rhinology. 2011; 49: 347-355.

54. Becker SS, de Alarcon A, Bomeli SR, Han JK, Gross CW. Risk factors for recurrent sinus surgery in cystic fibrosis: review of a decade of experience. Am J Rhinol. 2007; 21: 478-482.

55. Duplechain JK, White JA, Miller RH. Pediatric sinusitis. The role of endoscopic sinus surgery in cystic fibrosis and other forms of sinonasal disease. Arch Otolaryngol Head Neck Surg. 1991; 117: 422-426.

56. Halvorson DJ, Dupree JR, Porubsky ES. Management of chronic sinusitis in the adult cystic fibrosis patient. Ann Otol Rhinol Laryngol. 1998; 107: 946-952.

57. Umetsu DT, Moss RB, King WV, Lewiston NJ. Sinus disease in patients with severe cystic fibrosis: relation to pulmonary exacerbation. Lancet. 1990; 335: 1077-1078.

58. Cho DY, Hwang PH. Results of endoscopic maxillary mega-antrostomy in recalcitrant maxillary sinusitis. Am J Rhinology. 2008; 22: 658-662.

59. Coste A, Idrissi F, Beautru R, et al. Endoscopic endonasal ethmoidectomy in severe sinusitis of cystic fibrosis. Mid-term results in 12 patients. Ann Otolaryngol Chir Cervicofac.
1997; 114: 99-104

60. Jones JW, Parsons DS, Cuyler JP. The results of functional endoscopic sinus (FES) surgery on the symptoms of patients with cystic fibrosis. Int J Pediatr Otorhinolaryngol. 1993; 28: 25-32.

Dr. Kristian Macdonald

190 Elizabeth St.

Toronto ON

M5G 2N2, Canada

Tel: +1-416-946 8739

Fax: +1-416-946 8744

E-mail:kristian.macdonald@gmail.com

\section{Appendix}

\section{NICE* Quality assessment for Case series}

1. Case series collected in more than one centre, i.e. multi-centre study

2. Is the hypothesis/aim/objective of the study clearly described?

3. Are the inclusion and exclusion criteria (case definition) clearly reported?

4. Is there a clear definition of the outcomes reported?

5 . Were data collected prospectively?

6 . Is there an explicit statement that patients were recruited consecutively?

7. Are the main findings of the study clearly described?

8. Are outcomes stratified? (e.g., by disease stage, abnormal test results, patient characteristics)

Yes $=1 ;$ No $=0$ Score: $\quad / 8$

*NICE: National Institute for Health and Clinical Excellence

Available at:

http://www.nice.org.uk/nicemedia/pdf/Appendix_04_qualityofcase_series_form_preop.p df [accessed 21.08.11] 